\title{
Pain in medical inpatients: an under-recognised problem?
}

\author{
${ }^{1}$ A Conway Morris, ${ }^{2} \mathrm{~N}$ Howie \\ ${ }^{1,2}$ Pre-registration House Officer, Department of Anaesthesia, Southern General Hospital, Glasgow, UK
}

\begin{abstract}
Pain is a common feature of a range of illnesses. Although it is perceived as a significant problem for surgical patients and those with terminal malignancy, there is a paucity of evidence regarding the prevalence of pain in general medical patients. This study set out to determine pain prevalence and the contribution of chronic pain in a teaching hospital medical unit. All wards on the medical unit were visited on three consecutive days and all eligible patients were asked to complete a questionnaire indicating occurrence and severity of pain. Their analgesic prescriptions were also reviewed. A total of I 56 patients took part, representing $85 \%$ of all inpatients. Chronic pain prior to admission was a common finding, being reported by 57 (37\%) of patients and was associated with the occurrence of pain and severe pain (pain score $>6$ ) while an inpatient. Overall, $53 \%$ of patients experienced pain, $38 \%$ had severe pain and $18 \%$ had less than $50 \%$ analgesic efficacy. Prescription of non-recommended analgesics was common, and was strongly associated with the occurrence of pain (odds ratio 12,95\% confidence interval 4-38). Large numbers of patients had contraindications to commonly prescribed medications. Dissatisfaction was closely linked to poor response to prescribed analgesics, non-recommended prescription and severe pain. Pain is common among medical patients. Chronic pain is a major problem and complicates the issue of analgesic prescription. There is considerable scope for improvement in the management of pain among medical patients. However, pain control for these patients is likely to be more complex than for surgical patients.
\end{abstract}

Published online December 2009

Correspondence to A Conway

Morris, Centre for Inflammation Research, University of Edinburgh,

47 Little France Crescent, Edinburgh EHI 6 4TJ, UK

tel. +44 (0) I 3 I 242655 I

e-mail mozza@doctors.org.uk

KEYWORDS Analgesia, general (internal) medicine, pain, prevalence, satisfaction

DECLARATION OF INTERESTS A Conway Morris has received an academic prize sponsored by Eli Lily and Company.

Pain management has been recognised as a significant issue in surgical practice for some time, with the development of teams of clinicians dedicated to this issue, generally termed 'acute pain teams'.' A major focus of palliative care for those with malignant disease is pain control. As such there is a considerable and growing evidence base concerning both these groups of patients. ${ }^{2,3}$ In recent years, acute pain teams have taken on a wider role, with increasing requests for consultations coming from medical specialties.'

Pain is a common presenting complaint in many medical conditions; however, it has been subjected to less investigation than pain in surgical patients. Two surveys have indicated that pain remains a significant problem in medical inpatient populations, with an estimated prevalence of $50-60 \%$. 45

Pain management in medical inpatients can be more complex than in surgical patients, as many patients will have pre-existing painful conditions or have experienced chronic pain. ${ }^{6}$ Modalities that are highly effective for acute surgical pain, such as epidural analgesia or opioids delivered by patient-controlled infusion, are frequently inappropriate or unfeasible in acute or acute-on-chronic pain arising from medical conditions. Furthermore, medical patients frequently have multiple co-morbidities which may contraindicate specific analgesic medications. ${ }^{7,8}$
Despite an increasing awareness of, and focus on, pain in medical patients it appears to remain a significant problem and continues to be under-treated. ${ }^{4,5}$ This study set out to determine the prevalence of pain in a medical inpatient population, to examine the relationship between pain experienced in hospital and pre-existing chronic pain and to survey the prescription and efficacy of analgesic medication.

\section{PARTICIPANTS AND METHODS}

This period-prevalence study was conducted in the 200bed medical unit of an urban teaching hospital. All major medical specialties were represented, with the exception of nephrology and neurology. Over a six-week period each of the eight wards was visited for three consecutive days and all patients aged 18 years or over were invited to participate. Exclusion criteria were inability to complete the questionnaire (e.g. cognitive or communication impairment) and declining to take part. Patients who had been included earlier and then transferred wards were not resurveyed.

Data were collected regarding the occurrence of pain over the previous 24 hours, pain scores (0-10 visual interval scale), analgesia use and administration, pain relief (0-10 visual interval scale) and satisfaction with pain management (dichotomous yes/no question). Data 
TABLE I Non-recommended analgesic prescriptions

\begin{tabular}{|l|}
\hline $\begin{array}{l}\text { Long-acting strong opioid with inadequate, inappropriate } \\
\text { or no breakthrough }\end{array}$ \\
\hline Once-daily prescription of long-acting strong opioid \\
\hline Low-dose codeine $(8-16 \mathrm{mg})$ \\
\hline $\begin{array}{l}\text { Equipotent breakthrough (e.g. regular co-codamol with } \\
\text { tramadol for breakthrough) }\end{array}$ \\
\hline $\begin{array}{l}\text { Compound medications containing less than } \\
500 \mathrm{mg} \text { paracetamol }\end{array}$ \\
\hline
\end{tabular}

were also extracted from the case notes and prescription charts regarding demographics, medical history of conditions commonly associated with pain (arthritis, musculoskeletal conditions, malignancy and neuropathy), use of analgesia prior to hospital admission and prescription and use of analgesia in hospital. Patients were also asked whether they had experienced pain in the month prior to admission.

We defined recommended and non-recommended prescription with assistance from a consultant in anaesthesia and pain management before undertaking data collection. These were based on established tenets of analgesia, ${ }^{2,3,9}$ such as using more potent analgesics for 'breakthrough pain' when background analgesia is insufficient ${ }^{9}$ and prescribing the most effective combinations of drugs. ${ }^{10}$ Those prescriptions regarded as non-recommended are shown in Table I. Severe pain was defined as a pain score of $\geq 6$, in line with similar studies. ${ }^{411,12}$ The effectiveness of analgesia was defined as a pain relief score (i.e. reduction in pain) of $\geq 50 \%$, in line with similar studies. ${ }^{13,14}$ Prior pain and/or use of analgesics at home for longer than one month was defined as chronic pain.

Comparisons of means were undertaken using t-test; categorical data and proportions were compared using the chi-square test. A p value of $<0.05$ was taken as significant.

As this was an audit of current practice and involved no interventions or additional testing, ethical approval was not sought in line with guidance from the local ethics committee.

\section{RESULTS}

A total of 183 patients were available to participate, of whom 27 were excluded due to inability to complete the questionnaire. Of the remaining 156 patients, all agreed to participate. As most patients were on the ward for more than one day during the study, a total of 358 'patient days' of data were collected. Demographic information, including details of admission diagnosis and the presence of preexisting painful conditions, is shown in Table 2.

In total 83 patients (53\% of all patients) reported pain at some point during the survey period; 56 (36\% of all
TABLE 2 Demographics and diagnostic groups on admission

\begin{tabular}{|l|l|}
\hline Mean age (range) & 69 years (29-95) \\
\hline Female (n) & $86(55 \%)$ \\
\hline Admission problem (n) & $28(18 \%)$ \\
\hline Malignancy (solid organ and haematological) & $16(10 \%)$ \\
\hline $\begin{array}{l}\text { Liver disease/gastroenterology } \\
\text { (excluding malignancy) }\end{array}$ & $29(19 \%)$ \\
\hline Cardiac & $24(15 \%)$ \\
\hline Respiratory (excluding malignancy) & $9(6 \%)$ \\
\hline Rheumatological (excluding malignancy) & $5(3 \%)$ \\
\hline Endocrine & $14(9 \%)$ \\
\hline $\begin{array}{l}\text { Stroke/acute neurology } \\
\text { (excluding malignancy) }\end{array}$ & $31(20 \%)$ \\
\hline $\begin{array}{l}\text { Other (including falls, urinary tract } \\
\text { infection, deep venous thrombosis) }\end{array}$ & $57(37 \%)$ \\
\hline Pre-existing painful conditions (n) & $7(4 \%)$ \\
\hline Malignancy & $27(17 \%)$ \\
\hline Rheumatological/musculoskeletal & $8(5 \%)$ \\
\hline Neuropathy & $15(10 \%)$ \\
\hline $\begin{array}{l}\text { Other (including gallstones, headaches, } \\
\text { peripheral vascular disease) }\end{array}$ & \\
\hline
\end{tabular}

Percentages are of all study participants.

TABLE 3 Comparison of those who did and those who did not experience pain in hospital

\begin{tabular}{|l|l|l|l|}
\hline Group/parameter & $\begin{array}{l}\text { No pain } \\
(\mathrm{n}=73)\end{array}$ & $\begin{array}{l}\text { Pain } \\
(\mathrm{n}=83)\end{array}$ & $\begin{array}{l}\mathbf{p} \\
\left(\chi^{2}\right)\end{array}$ \\
\hline \% female & 48 & $6 \mathrm{I}$ & $\mathrm{NS}$ \\
\hline Mean age (years) & 70 & 68 & $\mathrm{NS}$ \\
\hline $\begin{array}{l}\text { \% with previous chronic } \\
\text { pain }\end{array}$ & 16 & 54 & $\leq 0.00 \mathrm{I}$ \\
\hline
\end{tabular}

Percentages refer to the denominator at the head of the column.

patients) had a median score of $\geq 6$, indicating severe pain. A comparison between those patients who remained pain-free and those who experienced pain is shown in Table 3.

As seen in Table 2, 57 patients experienced pain for at least one month prior to admission (44 of these patients were on regular analgesics at home). These 57 individuals formed the 'chronic pain' group. Forty-five patients with chronic pain experienced pain during the study period, compared with only 38 patients with no previous history of pain. Table 4 shows the differences between these two groups of patients.

Although all those with pain received analgesia, 28 patients (34\% of those with pain) failed to obtain effective pain relief. The types of analgesics prescribed and contraindication prevalence are shown in Figure I (data collection occurred in 2004 prior to the withdrawal of rofecoxib and co-proxamol). 
TABLE 4 Characteristics of patients experiencing pain during the study period, subdivided into those with and those without chronic pain

\begin{tabular}{|l|l|l|l|}
\hline Group/parameter & $\begin{array}{l}\text { No chronic } \\
\text { pain }(\mathrm{n}=38)\end{array}$ & $\begin{array}{l}\text { Chronic } \\
\text { pain }(\mathrm{n}=45)\end{array}$ & $\mathbf{p}\left(\chi^{2}\right)$ \\
\hline \% female & 42 & 78 & $\leq 0.00 \mathrm{I}$ \\
\hline Mean age (years) & 68 & 69 & NS \\
\hline $\begin{array}{l}\text { \% median pain } \\
\text { score } \geq \mathbf{6}\end{array}$ & 58 & 78 & $\leq 0.00 \mathrm{I}$ \\
\hline $\begin{array}{l}\% \text { median pain } \\
\text { relief }<\mathbf{5 0 \%}\end{array}$ & 31 & 36 & NS \\
\hline$\%$ dissatisfied & 37 & 42 & NS \\
\hline
\end{tabular}

Percentages refer to the denominator at the head of the column.

TABLE 5 Comparison of patients satisfied and dissatisfied with their pain control

\begin{tabular}{|l|l|l|l|}
\hline Group/parameter & $\begin{array}{l}\text { Dissatisfied } \\
(\mathrm{n}=33)\end{array}$ & $\begin{array}{l}\text { Satisfied } \\
(\mathrm{n}=50)\end{array}$ & $\mathbf{p}\left(\chi^{2}\right)$ \\
\hline \% female & 64 & 60 & NS \\
\hline Mean age (years) & 68 & 69 & NS \\
\hline \% pain score $\geq \mathbf{6}$ & 88 & 51 & $\leq 0.00 \mathrm{I}$ \\
\hline \% pain relief $<\mathbf{5 0 \%}$ & 70 & 10 & $\leq 0.00 \mathrm{I}$ \\
\hline $\begin{array}{l}\text { \% with previous } \\
\text { chronic pain }\end{array}$ & 58 & 72 & NS \\
\hline
\end{tabular}

Percentages refer to the denominator at the head of the column

Non-recommended prescription was found, on at least one occasion, in 39 patients ( $25 \%$ of all study participants), 35 of whom experienced pain, 24 severe pain and 14 of whom achieved less than $50 \%$ pain relief. Compared with recommended prescriptions, those with non-recommended prescriptions were more likely to suffer pain (odds ratio [OR] 12, 95\% confidence interval $[\mathrm{Cl}]$ 4-38) and were more likely to be dissatisfied (OR 2.5, 95\% Cl I.06-5.5). There was a trend towards ineffective analgesia (i.e. failure to reduce pain scores by $50 \%$ or more), but this did not achieve significance (OR I.6, 95\% Cl 0.6-4).

Patient satisfaction was assessed by a simple yes/no question. In total, 33 patients expressed dissatisfaction with their pain control while in hospital. Table 5 shows how they compare to those patients who were satisfied with their pain control.

\section{DISCUSSION}

This study confirms the findings of previous surveys that indicate high rates of pain among general medical patients. ${ }^{4.5}$ In contrast to previous work, however, we report on the effect of pre-existing chronic pain as well as examining the impact of quality of prescribing on the occurrence of pain.

The prevalence of chronic pain was high, with this being found in $35 \%$ of all patients. As well as showing an

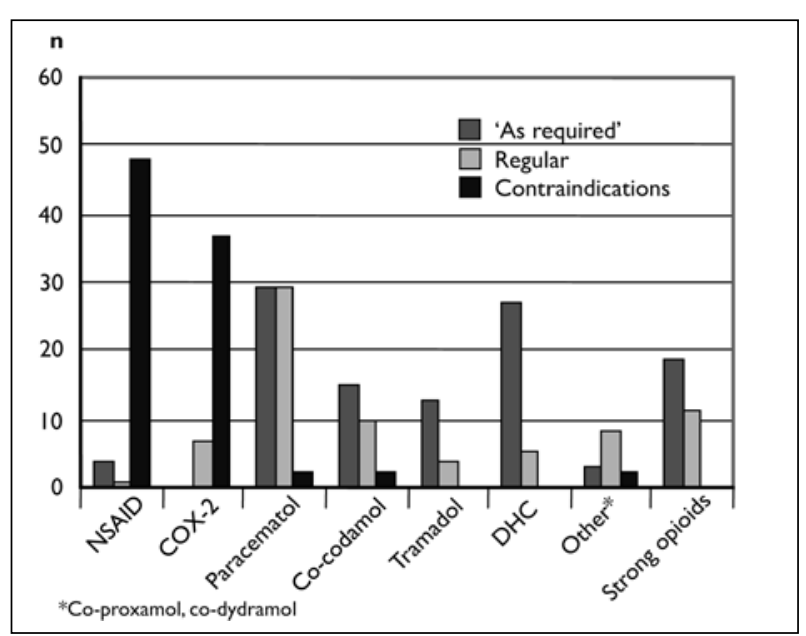

FIGURE I Analgesics prescribed and rates of contraindications. (COX-2 = cyclooxygenase -2 inhibitor, $\mathrm{DHC}=$ dihydrocodeine, NSAID $=$ non-steroidal anti-inflammatory drugs)

association with pain in hospital, chronic pain was also associated with a greater proportion of severe pain, although this did not translate into greater dissatisfaction or less effective analgesia. It is of note that women were over-represented in the chronic pain group; this may relate to a variety of factors, including differential occurrence of disease as well as perceptions and reporting of pain. ${ }^{15}$

Although it is not surprising that patients with a history of pain are more likely to experience pain in hospitals, this has important implications for patient management. Doctors are reluctant to prescribe strong opioids for non-malignant chronic pain ${ }^{16,17}$ and, indeed, this reluctance was reflected in the prescribing seen in this study. Chronic pain often requires a different approach to acute pain, using multimodal therapies and atypical analgesic agents. ${ }^{18}$ This can be complex, and is an area in which the junior doctors who manage many of the dayto-day issues of medical inpatients have little experience. It is likely that the high prevalence of chronic pain is, at least in part, responsible for the high rates of pain experienced by general medical inpatients.

Analgesic prescription occurred in all patients experiencing pain, and 'as required' analgesia was supplied promptly (all patients who requested prescribed analgesia reported administration within 10 minutes of their request). Although this finding is encouraging, it relied on patient self-reports and could not be externally verified. It is possible that patients were unwilling to criticise their care staff; however, their willingness to report severe pain and dissatisfaction would argue against this.

The types of analgesics reflect the population studied, non-steroidal anti-inflammatory drugs (NSAIDs) and cyclooxygenase-2 (COX-2) inhibitors being rarely used due to their high rates of contraindications. In combination with the issues around chronic pain outlined 
above, the highly co-morbid nature of this population adds further complexity to the management of pain.

However, it is apparent that analgesic prescription was haphazard in places, with considerable evidence of nonrecommended prescription. As can be seen from the associations with pain and dissatisfaction, this 'nonrecommended prescription' is not simply a matter of pharmacological niceties but had a real impact on patients. Although not included in our definition of non-recommended prescription there was a tendency to prescribe 'as required' analgesia even for patients with ongoing pain, rather than ensuring regular background analgesia.

We believe this study has a number of strengths: it was derived from a consecutive sample recruited from all the specialties that one may encounter in a general medical unit. The low rate of ineligibility (I5\%) and complete response rate of all eligible patients reduces risk of bias. Although the sample size is not large, results of both clinical and statistical significance were derived. A potential weakness is that by not recording pain location and type experienced by patients it is not possible to differentiate between chronic and acute-on-chronic pain, or indeed de novo acute pain occurring in a patient with chronic pain from another source. Furthermore, limited clinical and demographic data were collected, which reduces the ability to determine if the associations found are independent of other factors.

Further work is required to determine the optimal method of improving pain control for medical patients. Although the simple raising of awareness by studies such

\section{REFERENCES}

I Macintyre PE, Walker S, Power I et al. Editorial I: Acute pain management: scientific evidence revisited. $\mathrm{Br}$ J Anaesth 2006; 96:I-4. doi:I0.1093/bja/aei295

2 Royal College of Anaesthetists. Guidance on the provision of pain management services. In: Guidelines for the provision of anaesthetic services. London: Royal College of Anaesthetists; 1999. p. 55-9.

3 Scottish Intercollegiate Guidelines Network (SIGN). Control of pain in patients with cancer. Edinburgh: SIGN; 2008. Available from: http://www.sign.ac.uk/pdf/SIGNI06.pdt

4 Dix P, Sandhar B, Murdoch J et al. Pain on medical wards in a district general hospital. Br J Anaesth 2004; 92:235-7. doi: 10.1093/bja/aeh052

5 Whelan, CT, Jin L, Meltzer D. Pain and satisfaction with pain control in hospitalized medical patients: no such thing as low risk. Arch Intern Med 2004; 164:175-80. doi:10.100I/archinte.164.2.175

6 Clark JD. Chronic pain prevalence and analgesic prescribing in a general medical population. J Pain Symptom Manage 2002; 23:131-7. doi:I0.1016/S0885-3924(0I)00396-7

7 Oster G, Berger A, Dukes E et al. Use of potentially inappropriate pain-related medications in older adults with painful neuropathic disorders. Am J Geriatr Pharmacother 2004; 2: 163-70. doi: I0.1016/j. amjopharm.2004.09.005

8 Visser LE, Graatsma HH, Stricker BH. Contraindicated NSAIDs are frequently prescribed to elderly patients with peptic ulcer disease. $\mathrm{Br} J$ Clin Pharmacol 2002; 53:183-8. doi:I0.1046/j.0306-525I.200I.0II90.x

9 World Health Organization. WHO analgesic ladder. Available from http://www.who.int/cancer/palliative/painladder/en/ as this may be of benefit, experience from surgery and palliative care has shown that improvements have resulted from the implementation of evidence-based guidelines and provision of specialist 'pain teams'. More in-depth study of what leads to pain in hospitalised medical patients may be able to produce multimodal approaches to prevention and treatment.

This study highlights some problems that may be encountered in trying to improve pain control in medical patients. Chronic pain is common, is strongly associated with pain and severe pain during inpatient stays and often requires differing management to uncomplicated acute pain. The increased level of co-morbid conditions and higher age, compared to elective surgery populations, leads to restricted prescribing options due to higher levels of contraindications. Clearly simple transfer of surgical analgesic protocols would be inappropriate.

\section{CONCLUSIONS}

Pain is as common in medical patients as surgical patients, and is often severe. Despite this, specialist services are limited and prescribing is often sub-optimal, leading to poor pain control. The complex nature of many of these patients' medical problems and high rates of chronic pain means that tailored approaches would be required to tackle this problem.

Acknowledgements: The authors would like to thank Dr H Hosie, who suggested the project and helped draw up the definitions of non-recommended analgesia, and the staff and patients of the medical unit at the Southern General Hospital, Glasgow, for their co-operation.

10 Bandolier. The Oxford league table of analgesic efficacy. Available from: http://www.medicine.ox.ac.uk/bandolier/booth/painpag/ Acutrev/Analgesics/lftab.html

II Ekstein P, Szold A, Sagie B et al. Laparoscopic surgery may be associated with severe pain and high analgesia requirements in the immediate postoperative period. Ann Surg 2006; 243:4I-6. doi:I0.1097/0I.sla.0000193806.8I428.6t

12 Han KS, Lee KH; Korean Urologic Oncology Society Prostate Cancer Study Group. Factors influencing pain during transrectal ultrasonography-guided prostate biopsy. Prostate Cancer Prostatic Dis 2008; II:139-42. doi:I0.1038/sj.pcan.4501004

13 Taneri Z, Petersen-Braun M. [Double blind study of intravenous aspirin vs placebo in the treatment of acute migraine attacks.] Schmerz 1995; 9:I24-9. In German. doi:I0.I007/BF02530I30

I4 Siddall PJ, Molloy AR, Walker S et al. The efficacy of intrathecal morphine and clonidine in the treatment of pain after spinal cord injury. Anesth Analg 2000; 91 : 1493-8. doi: 10.1097/00000539. 2000I2000-00037

15 Holdcroft Al, Berkley KJ. Sex and gender differences in pain. In: McMahon SB, Koltzenberg M, editors. Wall and Melzack's textbook of pain. 5th ed. Edinburgh: Elsevier; 2005. p. I I8I-97.

16 Marks RM, Sachar EJ. Undertreatment of medical inpatients with narcotic analgesics. Ann Int Med 1973; 78: I73-8I.

17 Cohen SP, Raja SN. The middle way: a practical approach to prescribing opioids for chronic pain. Nat Clin Pract Neurol 2006; 2:580-I. doi:10.1038/ncpneuro0342

18 Hardy PA. Chronic pain management: the essentials. London: Greenwich Medical Media; 1997. 